\title{
Antecedents and Consequences of Goal Incongruity on New Product Development in Five Countries: A Marketing View
}

\author{
Jinhong Xie, Michael Song, and Anne Stringfellow*
}

This article examines an important challenge to effective cross-functional integration: goal incongruity among marketing, research and development $(R \& D)$, and manufacturing in new product development. We examine the effect of this incongruity as perceived by the marketing function on three components of cross-functional integration: the harmony of cross-functional relationships, the quality of cross-functional information, and the level of cross-functional involvement. We also examine how two types of managerially controllable variables affect goal incongruity: (1) factors that motivate functions to develop common goals; and (2) factors that facilitate the formation of such goals. We give special attention to the effect of national culture on the formation of common goals. Data collected from marketing managers in 1,083 firms in five culturally distinct areas-the United States, Great Britain, Japan, Hong Kong (a special administrative region of China), and mainland China - are used to test the hypothesized relationships. Our results underscore the importance of people-side issues, and of national culture, in cross-functional integration. Perceived goal incongruity among marketing, $R \& D$, and manufacturing impairs all three components of cross-functional integration. In United States and British firms, goal incongruity generally is attributed to motivational factors and in Japan and Hong Kong to facilitative factors. Finally, our results show that the two types of managerially controllable variables interact. For example, joint rewards and job rotation strengthen each other's tendency to reduce goal incongruity in all five samples. This suggests that job rotation promotes the development of joint goals more effectively when it is accompanied by a joint reward system.

\section{Introduction}

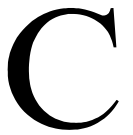

ross-functional integration long has been recognized as a key factor for improving new product success $[7,19]$. Various empirical studies have demonstrated its positive effect (e.g.,

\footnotetext{
* The authors thank Abbie Griffin, Barton A. Weitz, and three anonymous reviewers for their insightful comments. Financial support provided by Marketing Science Institute Research Competition Awards, Michael L. \& Myrna Darland Endowment and Center for Technology Entrepreneurship at the University of Washington, and University of Florida is acknowledged gratefully.

Address correspondence to Professor Michael Song, Center for Technology Entrepreneurship, University of Washington Business School, Box 353200, Seattle, WA 98195-3200. Telephone: (206) 5434587; E-mail: song@u.washington.edu.
}

$[11,28,29,59,62,63,66])$. Many firms have adopted systems to improve cross-functional integration to enhance the performance of new product programs $[25,55]$. However, to realize the potential benefits of such integration, firms not only must identify where and how to apply it, but they also must understand the human issues that may affect it $[10,26,67,77]$.

Human beings are complex combinations of skills, abilities, and emotions - not machine parts. Merely imposing a cross-functional structure for new product development (NPD) therefore cannot ensure that the functional representatives will work together effectively. If they are to commit themselves to a NPD project, participants must develop common 
goals [37]. Different functional areas in an organization have different specialized skills and knowledge; they deal with different parts of a firm's environment and have different roles and responsibilities. Their goals therefore often may be incompatible $[27,56,65]$. This incompatibility is likely to affect their desire and ability to participate actively in joint activities, to share information, and to synthesize expertise.

While goal differences between marketing and research and development (R\&D) have been recognized as a barrier to integration [26,55], their effect on specific aspects of cross-functional integration needs to be analyzed (e.g., the working relationships between the interdependent functions, the quality of information transferred across functional boundaries, and the extent of cross-functional joint activities). Furthermore, managerially controllable variables that facilitate the formation of common goals in NPD need to be identified and to be tested empirically. All this must be done with full awareness of the effect of national culture on the formation of common goals.

\section{BIOGRAPHICAL SKETCHES}

Jinhong Xie is associate Professor of marketing in the Warrington College of Business at the University of Florida. Her research interests include new product development, new product strategy in high-tech markets, network effects, management of the crossfunctional interface, and national culture effects on new product development. She has published in Journal of Marketing, Journal of Marketing Research, Journal of Product Innovation Management, Management Science, Marketing Science, Journal of Service Research, Journal of International Marketing, and IEEE Transactions on Engineering Management.

Dr. Michael Song is executive director of the Center for Technology Entrepreneurship and professor of marketing at the University of Washington. He also holds the Michael L. and Myrna Darland Distinguished Chair in Entrepreneurship at the University of Washington and serves as advisory research professor in the Eindhoven Center for Innovation Studies at Eindhoven University of Technology. He received an M.S. from Cornell University and an M.B.A. and Ph.D. in business administration from the Darden School at University of Virginia. Dr. Song's current research interests include start-up high-tech firms, valuation of technology and new ventures, new product development, project risk assessment and management, entrepreneurship in high-technology environments, measuring values of technology and research and development $(\mathrm{R} \& \mathrm{D})$ projects, and technology portfolio evaluation. $\mathrm{He}$ is a frequent keynote speaker at international conferences, and his research articles have appeared in numerous journals and conference proceedings

Anne Stringfellow is assistant professor of marketing in the global business department at Thunderbird, the American Graduate School of International Management. Her research interests include the use of cross-functional, transglobal teams and networks in new product development, and global account management. She has published in Management Science.
We therefore have developed and have tested a detailed theoretical model of the antecedents and consequences of goal incongruity from which we have been able to provide some suggestions as to how managers may encourage the formation of the shared goals needed for product success.

We propose a conceptual framework that links managerially controllable variables to effective crossfunctional integration. We hypothesize that goal incongruity affects three major dimensions of crossfunctional integration: the harmony of cross-functional relationships, the quality of cross-functional information, and the level of cross-functional involvement. We examine how two types of managerially controllable variables affect goal incongruity: (1) those that motivate functions to develop common goals; and (2) those that facilitate the formation of such goals. We examine both the separate and joint (whether substitutive or complementary) effects of these variables. Finally, to understand the effects of cross-cultural differences on the NPD process, we test our conceptual model with data from marketing managers in 256 American firms, 214 British firms, 279 Japanese firms, 119 Hong Kong firms, and 215 mainland Chinese firms.

This research aids in understanding the mechanism of goal incongruity and its effects on cross-functional integration and thereby provides new suggestions for decreasing goal incongruity in firms located in a variety of different countries.

\section{Conceptual Model and Research Hypotheses}

As shown in Figure 1, we consider first the effects of goal incongruity on cross-function integration and then the causes of goal incongruity and how their effects on three components of cross-functional integration might be moderated or eliminated. Finally, we consider the effect of national culture on the relative importance of the antecedents of goal incongruity.

\section{Goal Incongruity}

We define goal incongruity as the extent to which members of marketing, R\&D, and manufacturing subscribe to different goals, use different decision criteria, and think differently about time. In developing new products, R\&D typically aims for longterm technology advances, whereas marketing aims for short-term profit; this may lead to conflicts of 


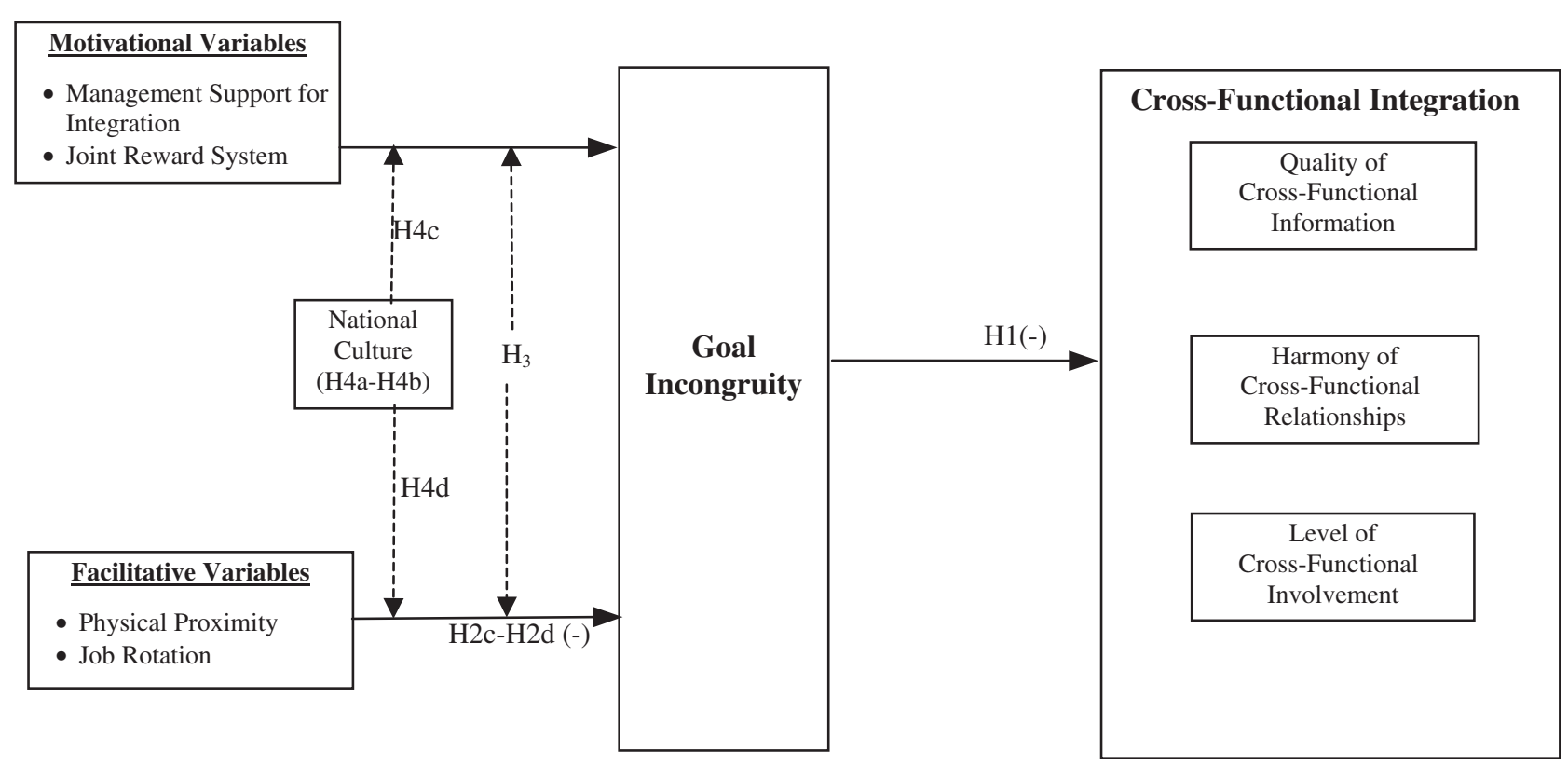

Note: The solid arrows indicate the direct effects and the dashed arrows indicate the interaction effects.

Figure 1. A conceptual model: antecedents and consequences of goal incongruity.

interest in project selection. Marketing's goals also may conflict with manufacturing's: Its focus on customer satisfaction leads it to demand a high degree of product variation, whereas manufacturing's focus on production efficiency and cost reduction leads it to prefer product standardization [61].

Research in organizational behavior has demonstrated the beneficial effects of shared goals on organizational performance $[44,50]$. Shared goals are particularly important where organizational members are interdependent, since each member controls contingencies that are vital for the others' task performance [51]. In the NPD literature, common goals are associated with new product success [20], while unclearly defined goals lead to disagreements between functions [59]. The literature on teams also strongly suggests the importance of common goals in ensuring that groups function as holistic entities rather than combinations of individuals with their own agendas [38].

\section{Effect of Goal Incongruity on Cross-Functional Integration}

Cross-functional integration traditionally has focused on the level of cross-functional involvement and the amount of cross-functional information flow $[3,29,63]$. From our in-depth interviews with firms undertaking product development in various countries, we found that effective cross-functional integra- tion is more than structured joint involvement and information flow. Just as important is the quality of the relationships among functions, without which mere interaction is of little use. To understand better how goal incongruity affects cross-functional integration, we therefore consider not two but three distinct components of cross-functional integration: (1) harmony of cross-functional relationships; (2) quality of cross-functional information; and (3) level of crossfunctional involvement.

Harmony of cross-functional relationships is defined as the extent to which departments maintain effective cooperative associations with one another. As organizations become less hierarchical, interemployee relationships in firms become increasingly important. For example, good relationships have been described as a key part of effective knowledge integration [24], while the productive nature of bargaining is believed to hinge on relationships among organizational group members [57]. In the NPD context, Souder [70] shows that 68 percent of projects conducted amid severe cross-functional disharmony failed.

Harmonious working relationships are characterized by give and take - by a willingness to honor commitments, to volunteer information, and to cooperate. In a cross-functional context, high-quality relationships involve a willingness to overcome functional boundaries and to "fill in the cracks" between strict functional responsibilities. Such rela- 
tionships are more likely between groups who perceive common goals [71]. Hence, we propose a negative relationship between goal incongruity and harmonious cross-functional relationships.

Quality of cross-functional information is defined as the extent to which credible, accurate information is disseminated in a timely fashion across functional boundaries. It differs from cross-functional harmony in that it involves a specific transfer of knowledge between departments. The perceived quality of information disseminated across functional boundaries affects whether or not that information is used [45]. The effective exchange of information between functions not only facilitates joint design but also ensures that all members of the product development effort are "on the same page," reducing redesign costs and time to market.

High-quality information is characterized by accuracy, credibility, and timeliness [48]. If the sender and receiver share common goals, the sender is motivated to provide more accurate information and to transmit it promptly [71]. For this reason we propose a negative relationship between goal incongruity and quality of cross-functional information.

Level of cross-functional involvement is defined as the extent to which functional areas participate together in activities that may be considered the major responsibility of another functional area. For example, the involvement of R\&D and/or manufacturing in analyzing market opportunities, traditionally considered the preserve of the marketing function. Joint cross-functional involvement is distinct from cross-functional relationships and crossfunctional information transfer in that it concerns not harmonious associations or data transmission but working side by side on a joint activity. By participating in joint activities, different functions gain first-hand cross-functional knowledge and experience [66]. Joint activities also allow for open discussion of opposing views, which is critical for making cooperative situations productive [71]. People prefer to interact with others who share similar goals [75]. Thus, where goals differ between functions, joint NPD activities will be less likely. Stating the above discussion more formally,

H1: The greater the level of goal incongruity, the lower the level of cross-functional integration measured by the harmony of cross-functional relationships, the quality of information disseminated across functional boundaries, and the level of cross-functional involvement.

\section{Antecedents of Goal Incongruity}

Two types of variables influence the formation of common goals: those that motivate the formation of shared goals and those that facilitate this process. Different functions perform different tasks and face different environments and different performance criteria. These differences naturally lead to the formation of suboptimal-local rather than optimal-firm-level goals. Unless the firm offers joint incentives, project participants will tend not to view the new product from the perspective of the firm as a whole. We consider two motivational variables: topmanagement support for cross-functional integration and joint reward systems.

Top-management support for cross-functional integration. Top-management support is an important determinant of R\&D-marketing integration in United States firms $[28,46,62,70]$ and of a climate favorable to innovation [73]. Employees tend to focus on activities they believe will be rewarded [40]. Topmanagement support for integration encourages cooperative efforts on project goals. It thus should promote the formation of joint goals and reduce goal incongruity.

Joint reward systems. Research suggests that goal conflicts are more likely when the reward system emphasizes the performance of individual departments rather than the organization as a whole [4]. Joint reward systems in which total, rather than functional, output is measured and is rewarded give functions economic incentives to achieve firm-level goals. Thus joint reward systems act via the expected outcome of the intergroup process as described by the expectancy theory of motivation [43]. Such incentive structures motivate the development of common goals and objectives [23,75], thus reducing the degree of goal incongruity.

The above arguments about the effects of motivational factors on goal incongruity are summarized in the following hypotheses:

H2a: The greater the top-management support for cross-functional integration, the less the goal incongruity.

H2b: The greater the use of joint rewards, the less the goal incongruity.

In addition to motivational factors that increase the willingness of NPD personnel to subscribe to common goals, there are facilitative factors that affect project members' ability to discover and agree on common 
goals. We consider two such factors: physical proximity and job rotation.

Physical proximity. Physical distance has been found to decrease communication [1] and performance on group projects [39]. More recent work has shown that the social impact of one person on another corresponds to the inverse square of the distance between them [42]. In new product development, colocation has been found to facilitate collaboration between R\&D and marketing [37].

Physical proximity not only makes cross-functional communication more likely but also promotes the use of rich media. The "richness" of communication media [12] is the extent to which they allow for interactive use of multiple communication modalities. For example, a face-to-face discussion represents a richer communication than an email message, since it allows both for interactivity and for the transfer of information by visual as well as audible means. Rich communication methods are more likely than others to lead to opinion change [56], which is important for the formation of shared goals. This suggests that goal incongruity is less likely among group members who work close to one another.

Job rotation. Job rotation is defined as the extent to which employees are assigned to areas outside their functional specialties in order to broaden their knowledge. Job rotation fosters cross-functional skills and increases understanding of the practices, procedures, problems, and goals of other functions [70], as well as of one's own function's place in the system as a whole. Thus job rotation not only should foster employees' skills but also should broaden their vision, reducing cross-functional goal incongruity.

The above arguments about the effects of facilitative factors on goal incongruity are summarized in the following hypotheses:

H2c: The greater the physical proximity among functions, the less the goal incongruity.

H2d: The greater the use of job rotation, the less the goal incongruity.

\section{Interaction between Antecedents}

We hypothesized that both motivational and facilitative variables are antecedents of goal incongruity in the preceding sections. Are there any interaction effects? Are the interactions complementary (i.e., Do they reinforce one another's effects on goal incongruity?) or substitutive (i.e., Do they counteract one another's effects on goal incongruity?)? More specifically, a complementary interaction effect would imply that opportunities for cross-functional interaction and learning work more effectively if there is motivation to develop common goals. A substitutive interaction effect would imply that implementing structures that physically bring people together are less important when the different parties involved in NPD are highly motivated to develop common goals. In the first case, motivational variables would seem to strengthen the effect of facilitative variables on goal incongruity and in the second to weaken it.

Understanding the relationship between the two types of antecedents has considerable relevance to managers. If the variables are complementary, managers will know that to emphasize one while ignoring the other is to waste resources. On the other hand, if the variables are substitutive and if facilitation, for example by colocation, is expensive, then a motivational substitute, such as joint rewards, could be implemented at a lower cost.

Since motivational variables create the willingness to set common goals and if facilitative variables are the means to set these goals, we believe that motivational and facilitative variables will strengthen each other's ability to reduce goal incongruity:

H3: There are interaction effects between motivational variables and facilitative variables on goal incongruity such that the two categories of antecedent act as complements for one another.

\section{Effect of National Culture}

The proposed conceptual model is grounded in Western literature on organizational behavior. Recent research suggests that the country in which a firm is located affects various aspects of organizational behavior $[9,15,32,77]$. It attributes this to various culture dimensions $[15,30,32,72]$. Two such dimensions seem likely to explain how national culture may affect the impact of the aforementioned motivational and facilitative variables: (1) individualism versus collectivism; and (2) high- versus low-context communication.

Individualism versus collectivism. Individualists view themselves primarily as individuals, pursue individual goals, and feel little emotional attachment to a core group [72]. In contrast, collectivists view themselves primarily as members of groups, pursue group goals, and feel strong attachment to the group 
[72]. The United States and Great Britain are individualistic societies according to the individualism-collectivism scale developed by Hofstede, on which they score 91 and 89 respectively [31]. Japan, Hong Kong, and mainland China are collectivist, scoring 46, 25, and 20, respectively on the same scale [32]. Research suggests that Western theories of group cooperation may not be applicable to collectivists [74] and that the degree of collectivism in a country affects the NPD process [49].

High-versus low-context communication. National cultures vary in the extent to which shared information is assumed in communication [30]. In low context cultures such as the United States and Great Britain, no common information is assumed to be shared $a$ priori by the sender and the receiver, and therefore messages are explicit. In high-context cultures, such as Japan and China, a pool of common knowledge is expected to assist in the interpretation of messages, and communications are less explicit, relying on the interpretation of subtle nuances and shades of meaning. Face-to-face contact therefore would seem more important to the formation of common goals in highcontext cultures.

Since collectivists naturally tend to identify with groups and to be more cooperative [74], less external motivation may be required to encourage the formation of group goals in collectivist cultures. At the same time, since people in high-context cultures have a high need for face-to-face communication, opportunities to socialize may be crucial to their achievement of common goals. We thus expect facilitative variables to be more effective than motivational variables in reducing goal incongruity in the three Asian countries.

In contrast, "the idea that collective wisdom creates the best decision is not part of the American work ethic" [41, p. 127], and the United States organizational structure is believed not to be conducive to cross-functional integration [52]. The usual reward systems in an individualistic society such as the United States measure individual achievement, not cooperation $[47,58]$. While it is still necessary to facilitate communication, we expect that motivation is the key to developing common goals among managers in an individualistic culture and that American and British firms therefore must provide strong incentives to induce different functions to develop common goals. Stated formally,

H4a: Motivational factors have a stronger effect than facilitative factors on goal incongruity in American and British firms.
H4b: Facilitative factors have a stronger effect than motivational factors on goal incongruity in Japanese, Hong Kong, and Chinese firms.

H4c: Motivational factors have a stronger effect on goal incongruity in American and British firms than in Japanese, Hong Kong, and Chinese firms.

H4d: Facilitative factors have a stronger effect on goal incongruity in Japanese, Hong Kong, and Chinese firms than in American and British firms.

\section{Methods}

Our overall research design, which combined case studies and survey research, followed the procedure for conducting cross-national comparative research outlined in Douglas and Craig [14] and extended by Song and Parry [65]. This section describes the development of the research instrument, the data collection procedures, and the measures used.

\section{Research Instrument Development}

We used a five-phase iterative procedure to develop our research instruments. First, we reviewed the literature for scales designed to measure the constructs examined in this study (e.g., [2,21,31]). Next, we conducted field interviews in 15 American firms, two British firms, eight Japanese firms, and one Hong Kong firm. The average group interview lasted four hours, though some ran as long as six hours. Of the 105 people interviewed, 36 were marketing managers, 41 were R\&D managers/directors, and 28 were manufacturing managers. The interviews in the United States, Great Britain, and Hong Kong were conducted in English; those in Japan were conducted in English with the assistance of an interpreter. The major objectives of the interviews were (1) to ensure the conceptual, functional, and category equivalence of the constructs; (2) to evaluate the appropriateness of the scales used in the North American interviews; (3) to generate new measurement items; (4) to investigate "theories-in-use;" and (5) to assess potential cultural bias in response formats.

The interviews consisted of two parts. The first part was designed to elicit salient constructs and participants' definitions of those constructs (e.g., goal incongruity), so as to assess their conceptual equivalence. We also asked managers to discuss whether or not several theoretical models adequately described their experiences and, if not, how they would modify 
the models. These discussions permitted us to assess the functional equivalence of constructs, the degree to which they serve the same function in different countries.

The second part of the interviews focused on developing new measures and on validating existing measures adapted from the literature. Managers were shown a list of scale items compiled from our literature review, earlier field research interviews, and case studies. They were asked to assess the extent to which each item measured the construct it was intended to measure and to suggest possible modifications and additions. These discussions permitted an assessment of the category equivalence of our constructs, the degree to which foreign and United States executives classify them according to the same scheme.

A content analysis of the interview data revealed important issues of cross-functional interface management and generated new items for the theoretical constructs. From these newly generated items, combined with those identified in the literature and validated in our interviews, we developed an initial pool of questionnaire items.

We followed the paradigm for developing better marketing measures [18] to identify subsets of the generated and validated measures that were unique and possessed "different shades of meaning." We administered the questionnaire to all of the participants in the second phase to refine the measures. We then analyzed the data to assess the reliability of each item. We reworded some items and deleted all items with low reliability. In addition, after identifying subsets of the final items that were unique and possessed "different shades of meaning," we requested a panel of eight academic experts and executives to evaluate a list of constructs and corresponding measurement items for clarity, specificity, and representativeness.

Based on feedback from the panel, we prepared the English version of the questionnaire and then translated it using two parallel-translation/doubletranslations $[14,60]$. Two translators independently provided Japanese versions, and two more independently translated those Japanese versions back to English; then all four met with us to resolve minor discrepancies. The Chinese translations were produced in the same way.

The resulting questionnaires were pretested on 12 bilingual M.B.A. students from two well-regarded United States business schools and the participants in the field research mentioned earlier. After the pretests, measures were modified and the instruments were drafted professionally.

\section{Data Collection}

The sampling frame for the United States, Great Britain, Hong Kong, and China consisted of all nonservice firms listed in the World Business Directory. The Japanese sampling frame consisted of all public nonservice Japanese companies traded on the Tokyo, Osaka, and Nagoya stock exchanges. We randomly selected 500 firms in the United States, 500 in Great Britain, 500 in Japan, 300 in Hong Kong, and 500 in China as our final survey samples (with appropriate industry stratification to match the samples).

In administering the final mail survey, we adapted the Total Design Method for survey research [13] with the modification suggested by Song and Parry [65]. The first mailing packet included a personalized letter, the appropriate language questionnaire, and a postage-paid envelope with an individually typed returnaddress label. We asked the contact person (president, vice president of marketing, or $R \& D$ director) to distribute the questionnaire to a marketing manager in a high-tech division, defined as the division developing at least four new products in the following areas: chemicals and related products; electronic and electrical equipment; pharmaceutical, drugs, and medicines; industrial machinery and equipment; telecommunications equipment; semiconductors and computer-related products; and instruments and related products. A marketing manager was selected as the key informant from each firm because of the importance of the marketing/R\&D interface in the NPD process and because marketing managers seemed most likely to be aware of goal incongruity in firms developing technical products [76].

After four follow-up letters, phone calls, and/or facsimiles, we received questionnaires from 256 firms in the United States, from 214 firms in Great Britain, from 279 firms in Japan, from 119 firms in Hong Kong, and from 215 firms in China. After adjustments for returned mail and unusable questionnaires, the response rates were 51 percent for the United States, 43 percent for Great Britain, 56 percent for Japan, 40 percent for Hong Kong, and 43 percent for China.

The industries [and standard industry classification (SIC) codes] represented in the final samples are 
chemicals and related products (28); electronic and electrical equipment (36); pharmaceutical, drugs, and medicines (2833, 2834, 2835, 2836, 5047); industrial machinery and equipment (35); telecommunications equipment (3661, 2663 2669, 4812, 4813, 4822, 3669, $723.9,724.1,724.2)$; semiconductors and computerrelated products $(35,36)$; and instruments and related products (38).

\section{Measures}

This section presents definitions and an overview of the measures; detailed measurement items and their sources are provided in the Appendix.

Cross-functional integration. Cross-functional integration is measured by three distinct components. Harmony of cross-functional relationships includes general satisfaction with the relationships, sense of responsibility and commitment to each other, collaborative attitudes, and open communications (four items). Quality of cross-functional information includes the accuracy, promptness, and timeliness of information exchanged among the three areas (three items). Level of cross-functional involvement includes cross-functional involvement among marketing, $\mathrm{R} \& \mathrm{D}$, and manufacturing in conducting NPD activities (six items).

Goal incongruity. This construct measures the extent to which the goals, time orientations, and decision criteria of marketing, $\mathrm{R} \& \mathrm{D}$, and manufacturing seem to differ (three items).

Motivational variables. The items for joint reward systems assess the extent to which project members are evaluated and are rewarded for joint instead of individual performance (three items). Management support for integration measures the degree to which management provides resources and delegates authority to support cross-functional integration efforts (three items).

Facilitative variables. Physical proximity measures the degree of colocation of the marketing, $R \& D$, and manufacturing functional areas. Job rotation measures the extent to which the firm emphasizes and practices job rotation across functional areas (two items).

For each construct, we computed item-total correlation and the coefficient alpha to identify badly fitting items. We deleted items that had low item-to-construct loadings to improve the internal consistency of the scales $[6,8]$. Table 1 presents summary statistics and reliabilities of the constructs. These reliabilities range from 0.57 to 0.82 , and most of them are above 0.70 . With the exception of the scales for joint rewards in Japan and Hong Kong, which are below 0.60 , they can be judged to be in the acceptable range as suggested in the literature $[53,54]$.

\section{Analysis and Results}

\section{Test of Mediation}

Our model suggests that goal incongruity mediates the effect of two types of managerially controllable variables on cross-functional integration. Since the literature [26,62] has suggested direct links between these variables and cross-functional integration, before examining the antecedents and consequences of goal incongruity using the proposed model, we first tested the mediating effects using criteria recommended by Baron and Kenny [5]. We performed three regression models as recommended by Judd and Kenny [36]: (1) the mediator on the independent variable $\left(m=a x+e_{m}\right) ;(2)$ the dependent variable on the independent variable $\left(y=c x+e_{y}\right)$; and (3) the dependent variable on both the independent variable and on the mediator $\left(y=c^{\prime} x+b m+e\right)$. Mediation can be established if $c^{\prime}$ is insignificant (full mediation) or less than $c$ (partial mediation) given that both $a$ and $c$ are significant.

We tested the mediating effects for all four independent variables, three dependent variables, and five samples. The mediating effect was established in 83 percent of the cases ( 29 out of 35 ) where the direct effects were significant. Among them, 13 involved full and 16 partial mediation (Japan: five full and five partial; Hong Kong: three full and one partial; China: three full and two partial; United States: one full and five partial; Great Britain: one full and three partial). These results provide strong support for the mediating effect of goal incongruity on the relationship between these managerially controllable variables and cross-functional integration.

\section{Hypothesis Testing}

The proposed relationships were tested using three-stage least-squares (3SLS) regression analysis. 


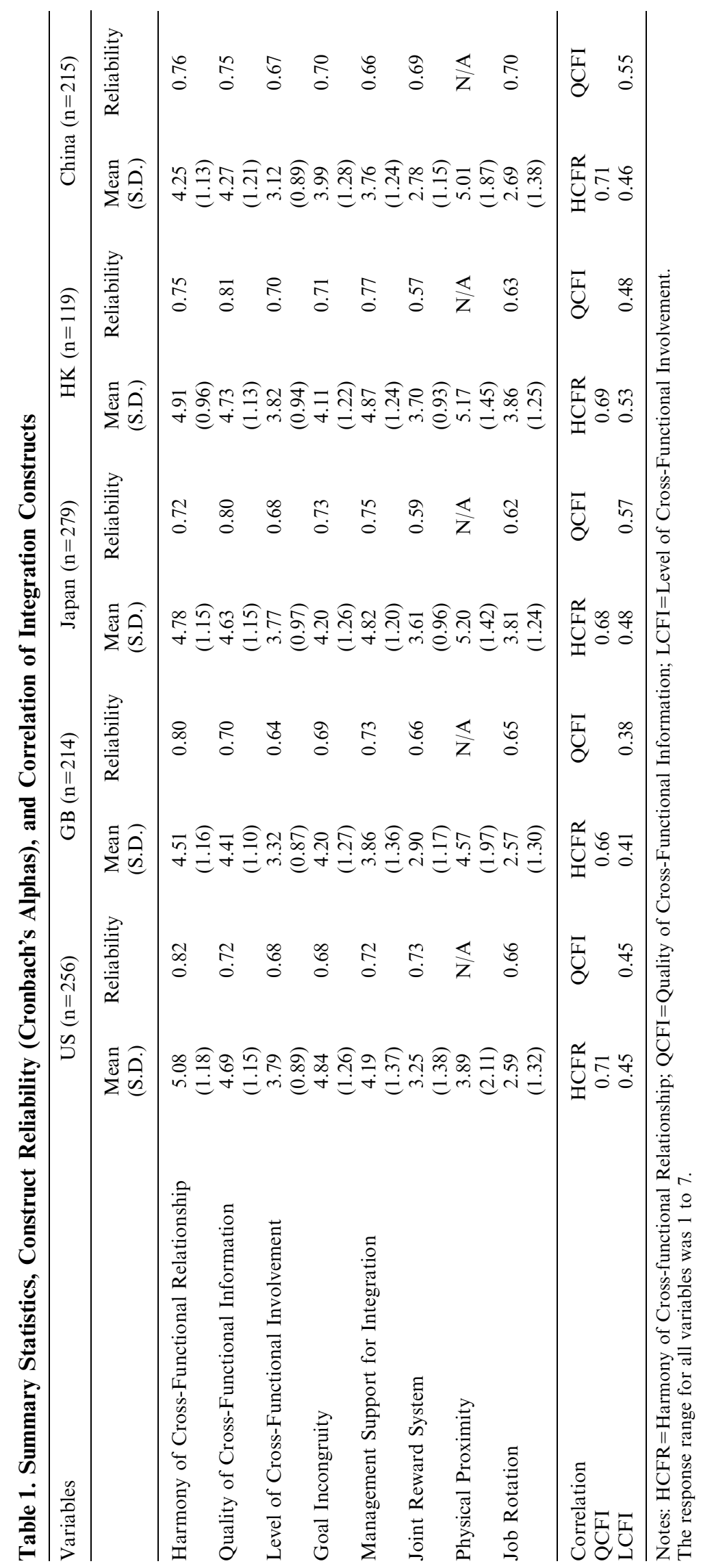


We used 3SLS because the equations were interdependent, i.e., the dependent variables from some equations appeared as independent variables in other equations. In such a system, ordinary leastsquares (OLS) estimates can be inconsistent. 3SLS estimation provides consistent and efficient parameter estimates of models incorporating reciprocal causation and interdependent error terms. To reduce potential multicollinearity problems, we mean-centered all the independent and dependent variables in the regression models as suggested by Jaccard et al. [34]. Note that, in testing the relationship between goal incongruity and cross-functional integration, we control for the direct effects of the two types of managerially controllable variables on cross-functional integration suggested by the literature
$[26,62]$. The 3 SLS regression results are presented in Table 2.

To examine the effect of national culture on the relative importance of motivational and facilitative variables, we ran t-tests on each pair of the coefficients; these measured the equality of the coefficients within each country using the procedure provided in the statistical analysis software (SAS) program. These results are shown in the upper section of Table 3. To test the cross-country differences, we further used a four-dummy variable regression and compared the regression coefficients across the Asian and Western groups. The results of these comparisons are shown in the lower section of Table 3.

Consequences of Goal Incongruity. The upper portion of Table 2 shows partial support for the

Table 2. Three-Stage Least-Squares Estimation Results

\begin{tabular}{|c|c|c|c|c|c|}
\hline $\begin{array}{l}\text { Independent } \\
\text { Variables }\end{array}$ & US & GB & Japan & $\mathrm{HK}$ & China \\
\hline Model: Consequences of Goal Incongruity & \multicolumn{5}{|c|}{$\underline{\text { Dependent Variable }=\text { Harmony of Cross-Functional Relationship }}$} \\
\hline Intercept & 0.06 & 0.03 & 0.03 & 0.03 & 0.00 \\
\hline Goal Incongruity & $-0.39 * * *$ & -0.20 & $-0.36 * * *$ & $-0.45 * * *$ & 0.22 \\
\hline Management Support for Integration & $0.26 * * *$ & $0.24 * * *$ & $0.12 * * *$ & 0.03 & $0.29 * * *$ \\
\hline Joint Reward System & -0.08 & 0.11 & 0.07 & 0.10 & $0.27 * *$ \\
\hline Physical Proximity & 0.03 & -0.02 & $0.08 * *$ & 0.02 & 0.08 \\
\hline \multirow[t]{2}{*}{ Job Rotation } & $0.13 * * *$ & -0.02 & $0.06 *$ & 0.02 & 0.07 \\
\hline & \multicolumn{5}{|c|}{ Dependent Variable =Quality of Cross-Functional Information } \\
\hline Intercept & 0.02 & 0.03 & 0.02 & 0.03 & 0.03 \\
\hline Goal Incongruity & $-0.33^{* *}$ & $-0.47 * * *$ & $-0.60 * * *$ & $-0.75^{* * *}$ & $-0.75^{* * *}$ \\
\hline Management Support for Integration & $0.27 * * *$ & $0.12 * *$ & 0.02 & 0.00 & 0.11* \\
\hline Joint Reward System & -0.09 & -0.02 & 0.02 & -0.05 & -0.16 \\
\hline Physical Proximity & -0.01 & $-0.08 * *$ & 0.01 & -0.05 & $-0.18^{* *}$ \\
\hline \multirow[t]{2}{*}{ Job Rotation } & $0.14 * * *$ & 0.01 & 0.00 & -0.04 & 0.01 \\
\hline & \multicolumn{5}{|c|}{$\underline{\text { Dependent Variable }=\text { Level of Cross-functional Involvement }}$} \\
\hline Intercept & 0.00 & -0.01 & 0.00 & -0.01 & -0.04 \\
\hline Goal Incongruity & -0.07 & -0.01 & $-0.22 * * *$ & $-0.28 * *$ & $-0.51 * * *$ \\
\hline Management Support for Integration & $0.14 * * *$ & $0.16 * * *$ & $0.20 * * *$ & $0.17 * * *$ & $0.24 * * *$ \\
\hline Joint Reward System & -0.04 & -0.01 & -0.04 & -0.05 & $0.29 * * *$ \\
\hline Physical Proximity & 0.03 & 0.00 & -0.03 & $-0.11^{*}$ & $0.14 * *$ \\
\hline Job Rotation & $0.17 * * *$ & $0.07 *$ & $0.13^{* * *}$ & $0.11^{*}$ & $0.13 * * *$ \\
\hline Model: Antecedents of Goal Incongruity & \multicolumn{5}{|c|}{$\underline{\text { Dependent } \text { Variable }=\text { Goal Incongruity }}$} \\
\hline Intercept & 0.04 & -0.02 & $0.19 * * *$ & $0.19 * *$ & 0.01 \\
\hline Management Support for Integration & $-0.21^{* * *}$ & $-0.18 * * *$ & $-\mathbf{0 . 0 7 *}$ & -0.06 & -0.07 \\
\hline Joint Reward System & $-0.42 * * *$ & $-0.51 * * *$ & $-0.27 * * *$ & $-0.26 * * *$ & $-0.46^{* * *}$ \\
\hline Physical Proximity & $-0.16 * * *$ & $-0.18 * * *$ & $-0.19 * * *$ & $-0.24 * * *$ & $-0.25^{* * *}$ \\
\hline Job Rotation & $-\mathbf{0 . 0 8 * *}$ & $-0.08 *$ & $-0.22 * * *$ & $-0.21 * * *$ & $-0.11 * *$ \\
\hline (Management Support) x (Physical Proximity) & $-0.04 * *$ & $-0.05 * *$ & -0.04 & -0.04 & 0.00 \\
\hline (Management Support) x (Job Rotation) & $0.09 * *$ & $0.17 * * *$ & $0.27 * * *$ & $0.19 * * *$ & $0.14 * * *$ \\
\hline (Joint Reward System) x (Physical Proximity) & $0.13 * * *$ & $0.11^{* * *}$ & $-0.10 * *$ & -0.09 & 0.03 \\
\hline (Joint Reward System) x (Job Rotation) & $-0.09 * *$ & $-0.16 * * *$ & $-0.40 * * *$ & $-0.37 * * *$ & $-\mathbf{0 . 0 7 * *}$ \\
\hline Weighted System $\mathbf{R}^{2}$ & 0.33 & 0.29 & 0.26 & 0.29 & 0.26 \\
\hline
\end{tabular}

Note: GB represents Great Britain and HK represents Hong Kong.

$* * * \mathrm{p}<0.01$

$* * \mathrm{p}<0.05$

$* \mathrm{p}<0.1$ 
Within-Country Comparison of Regression Coefficients

\begin{tabular}{|c|c|c|c|c|c|}
\hline & U.S. & GB & Japan & $\mathrm{HK}$ & China \\
\hline $\begin{array}{l}\text { Management Support vs. } \\
\text { Physical Proximity }\end{array}$ & $\mathrm{ns}$ & $\mathrm{ns}$ & $\mathrm{F}>\mathrm{M}^{* *}$ & $\mathrm{~F}>\mathrm{M}^{* *}$ & $\mathrm{~F}>\mathrm{M}^{* * *}$ \\
\hline $\begin{array}{l}\text { Management Support vs. } \\
\text { Job Rotation }\end{array}$ & $\mathrm{M}>\mathrm{F}^{* *}$ & ns & $\mathrm{F}>\mathrm{M}^{* *}$ & $\mathrm{~F}>\mathrm{M}^{*}$ & ns \\
\hline $\begin{array}{l}\text { Joint Reward System vs. Physical } \\
\text { Proximity }\end{array}$ & $\mathrm{M}>\mathrm{F}^{* * *}$ & $\mathrm{M}>\mathrm{F}^{* * *}$ & ns & ns & $\mathrm{M}>\mathrm{F}^{* * *}$ \\
\hline Joint Reward System vs. Job & $\mathrm{M}>\mathrm{F}^{* * *}$ & $\mathrm{M}>\mathrm{F}^{* * *}$ & ns & ns & $\mathrm{M}>\mathrm{F}^{* * *}$ \\
\hline
\end{tabular}

Between-Countries Comparison of Regression Coefficients

\begin{tabular}{|c|c|c|c|c|c|c|}
\hline & U.S. vs. Japan & U.S. vs. HK & U.S. vs. China & GB vs. Japan & GB vs. HK & GB vs. China \\
\hline Management Support & U.S. $>$ Japan** & U.S. $>\mathrm{HK}^{*}$ & U.S. $>$ China** & GB $>$ Japan* & ns & GB > China* \\
\hline Joint Reward System & U.S. $>$ Japan** & U.S. $>\mathrm{HK}^{*}$ & ns & $\mathrm{GB}>\mathrm{Japan}^{* * *}$ & $\mathrm{~GB}>\mathrm{HK}^{* * *}$ & ns \\
\hline Physical Proximity & & ns & U.S. $<$ China** & ns & ns & GB $<$ China* \\
\hline Job Rotation & U.S. $<$ Japan** & ns & ns & GB $<$ Japan*** & $\mathrm{GB}<\mathrm{HK}^{*}$ & ns \\
\hline
\end{tabular}

Notes: $\mathrm{M}$ and $\mathrm{F}$ indicate the absolute value of motivational and facilitative coefficients, respectively. GB represents Great Britain and HK represents Hong Kong.

$* * * \mathrm{p}<0.01$

$* * \mathrm{p}<0.05$

$* \mathrm{p}<0.1$

ns: $\mathrm{p} \geq 0.1$.

hypothesized negative relationships between marketing's perceived goal incongruity and the three integration constructs $(\mathrm{H} 1)$. Goal incongruity is related negatively to cross-functional harmony in the United States, Japan, and Hong Kong to the quality of cross-functional information in all five samples and to the level of cross-functional involvement in Japan, Hong Kong, and China.

Antecedents of goal incongruity. The lower section of Table 2 shows that joint reward systems (H2b), physical proximity $(\mathrm{H} 2 \mathrm{c})$, and job rotation $(\mathrm{H} 2 \mathrm{~d})$ are associated with decreased levels of goal incongruity in all five samples, supporting the hypothesized negative effects. While management support for integration $(\mathrm{H} 2 \mathrm{a})$ is related negatively to goal incongruity in American, British, and Japanese firms, the relationship is not significant in Hong Kong and China.

Hypothesis $\mathrm{H} 3$ predicts that there will be complementary interaction effects between motivational and facilitative antecedents of goal incongruity. This hypothesis is supported partially. Note that when the main effects of both variables are negative, a negative interaction implies that the two variables strengthen each other's effect (a complementary relationship), and a positive interaction implies that they weaken each other's effect (a substitutive relationship). The lower section of Table 2 shows that management support and physical proximity are complementary in American and British firms. Management support for integration and job rotation are substitutive in all five samples. Joint reward systems and physical proximity are substitutive in the United States and Great Britain but are complementary in Japan. Finally, joint rewards and job rotation are complementary in all five samples.

Within-country comparisons. $\mathrm{H} 4 \mathrm{a}$ predicts that motivational factors are more important than facilitative factors in reducing cross-functional goal incongruity in Western firms, while $\mathrm{H} 4 \mathrm{~b}$ predicts that facilitative factors are more important than motivational factors in Asian firms. The results shown in the upper section of Table 3 indicate that both hypotheses are supported partially. For the American and British samples, the motivational coefficients are more negative in all cases where there are significant differences. For the Japanese and Hong Kong samples, the effect is opposite: Facilitative effects dominate motivational effects where there are significant differences. However, for the Chinese sample, of three significant differences only one is in the hypothesized direction.

Between-country comparisons. $\mathrm{H} 4 \mathrm{c}$ predicts that motivational factors are more important in reducing cross-functional goal incongruity in Western firms 
than in Asian firms, while $\mathrm{H} 4 \mathrm{~d}$ predicts that facilitative factors are more important in Asian firms than in Western firms. The results of the crosscountry comparisons presented in the lower section of Table 3 show that in all cases where significant differences are found between Western and Asian countries, the hypothesized directions are supported.

\section{Discussion}

A summary of our results is presented in Table 4. Before discussing our results and their implications, we should point out that our descriptive research design precludes us from making causal inferences from the results. Moreover, our data were collected from a single function - marketing. Further caveats in interpreting our findings are provided in the Limitations section later in the article.

Despite these qualifications, our empirical results lead to a number of generalizable associations that hold in American, British, Japanese, Hong Kong, and Chinese firms and also reveal several interesting differences among countries. In the following section, we first discuss the similarities among the countries and then the differences.

\section{Similarities among Countries}

First, in all five samples, there is a significant negative relationship between goal incongruity and the quality of cross-functional information. This suggests that developing common goals among functions engaged in NPD programs may improve this component of cross-functional integration, regardless of cultural norms.

Second, joint rewards are significantly associated with reduced goal incongruity in all five samples. This suggests that, even in collectivist countries, it may be useful to encourage the formation of common goals by providing rewards that depend on the overall product development outcome rather than merely on the performance of a particular functional area.

Third, in addition to joint rewards, physical proximity also is associated significantly with reduced goal incongruity in all five samples. Despite recent improvements in information technology, physical proximity still appears to play an important role in the formation of common goals and objectives.

Fourth, in all five samples, there is a significant negative relationship between job rotation and goal incongruity, suggesting the importance of allowing employees to gain a greater understanding of other functional areas by moving between them.

Fifth, general support is found for the hypothesized complementary relationship between joint rewards and job rotation (a negative interaction). This suggests that job rotation will facilitate more effectively the development of joint goals if it is accompanied by a joint reward system. Joint rewards seem to provide strong incentives for job rotation participants to broaden not only their skills but also their vision of the work of other functions so as to better understand other functions' objectives, time orientations, and decision criteria.

Finally, contrary to our hypothesis, management support for integration and job rotation appears to be substitutive (a positive interaction) in all five samples. This suggests that top-management support for crossfunctional integration weakens the effect of job rotation on the formation of common goals. One possible explanation for this surprising result is that where management supports cross-functional interaction and communication, sufficient resources already are allocated to facilitate it. It also may imply that more integration-oriented organizational structures and mandated consensus decision processes are already in place. If this is true, standard job rotation practice will be less important in reducing goal incongruity.

\section{Differences among Countries}

First, our findings show a significant negative association between goal incongruity and the harmony of cross-functional relationships for American, Japanese, and Hong Kong firms but not for those in Great Britain and mainland China. It thus appears that the absence of common goals reduces the quality of cross-functional relationships in some but not all countries. Further research is needed to investigate the cultural or other issues that may underlie this result.

Second, the negative relationship between goal incongruity and cross-functional involvement was supported in Japan, Hong Kong, and China but not in the United States or Great Britain. This may be because cross-functional involvement in the two Western countries usually is mandated by standard operating procedures so that it occurs regardless of common goals. 


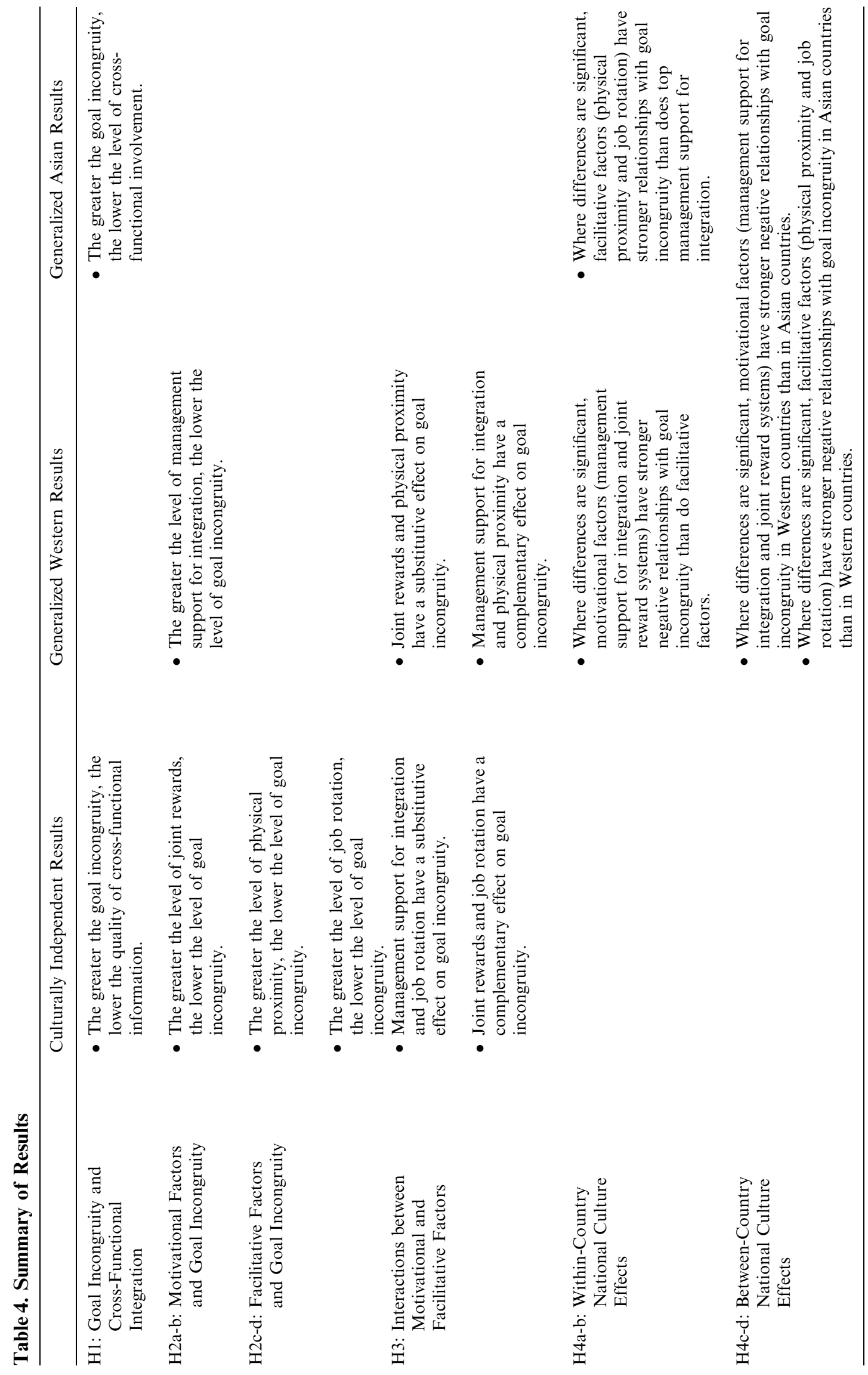


Third, our results suggest that the negative relationship between motivational variables and goal incongruity generally is stronger in American and British firms than in Japanese and Hong Kong firms. It also appears that facilitative variables affect goal incongruity in Japanese and Hong Kong firms as much as or more than in American and British firms. These results support the hypothesized national culture effects. They suggest the importance of providing motivation for people to develop shared goals in countries with strong individualistic cultures. They also suggest the importance of providing opportunities for people to build shared goals in collectivist and high-context cultures.

Fourth, management support and physical proximity appear to have a complementary relationship in the two Western countries but not in the Asian countries. This implies that in the Western countries, reducing physical distance between functions may not work as well as it should if top management shows no strong support for cross-functional integration by formally promoting cross-functional teams and by setting clear goals and high standards for team work. This may be unnecessary in Asian countries if employees regard themselves as part of the same ingroup (the firm).

Fifth, joint rewards are found to substitute for physical proximity in the two Western samples but not in the three Asian samples. This suggests that, in the United States and Great Britain, joint rewards lead functions to increase their communication, which weakens the role of physical proximity between functions in promoting common goals and objectives. Why does the same substitution effect not appear in the Asian samples? While a joint reward system motivates a higher level of communication between functions, it does not increase necessarily face-to-face interaction. Our results may suggest that the informal face-to-face contact is more critical in the formation of common goals in Asian countries in which close interaction with an in-group is vital.

Finally, while similar patterns are found in Japan and Hong Kong and in the United States and Great Britain, China deviates from its Asian counterparts. For example, the results of within-country comparisons show that, unlike Japanese and Hong Kong firms but like American and British firms, joint rewards, a motivational variable, appear to exert a stronger negative effect on goal incongruity than do the two facilitative variables in Chinese firms. This may reflect the increased emphasis in China on
American-style materialism, particularly among the younger generations $[17,33]$. In particular, the United States is viewed as a model for the future [22], and individual achievement is extremely important. Thus, as in the two Western countries, joint rewards are more effective than job rotation and physical proximity. Another contributory factor may be the increased prevalence of single-child families in Chinese society. Family planning legislation introduced in the 1970s permitted only one child per family. These children are now part of the labor force. Research has shown that these children are less group-oriented than children raised with siblings [35] and need motivation to establish group goals.

\section{Managerial Implications}

This study supports the importance of establishing common goals in achieving effective cross-functional integration in new product development. Our empirical results suggest several important findings for managers. First, the significant negative relationship between functional goal incongruity in NPD and our three components of cross-functional integration demonstrates the importance of understanding the human issues in cross-functional integration. It suggests that in addition to identifying activities that require integration and developing systems that increase it, managers need to promote common goals between functions involved in NPD.

Second, our results suggest the importance of a joint reward system in developing common goals. It is surprising that in many United States firms, marketing still is rewarded for increased market share and $\mathrm{R} \& \mathrm{D}$ for patents and publications, regardless of whether or not the new technology has led to marketshare improvements [26]. A recent United States study found that fewer than 20 percent of crossfunctional NPD team members received any teambased compensation [16]. Joint rewards therefore may represent an underused source of competitive advantage for United States firms.

Third, the interaction effects among the antecedents of goal incongruity indicate the importance of considering managerial interventions in their entirety rather than piecemeal. Some interventions may have less costly substitutes. For example, colocation is often costly, and reducing physical distance among cross-functional team members may require increasing physical distance among members within each function. The substitutive relationship between joint 
rewards and physical proximity found in the two Western counties suggests that it may be more efficient for American and British managers to rely exclusively on the first, less costly, alternative.

Fourth, the cross-country differences we identified suggest that processes successful in one country may not work in another - that tried-and-true procedures be adapted to local conditions. For example, to form common NPD goals, American and British firms might demonstrate strong top-management support for cross-functional integration rather than implement job rotation. Japanese, Chinese, and Hong Kong firms, on the other hand, might do better to implement such rotation.

\section{Limitations}

An important limitation of this research is that its design was cross-sectional descriptive. In interpreting the research results, we thus are unable to infer causal relationships; we only can identify associations between variables. In addition, the static nature of this research does not allow us to examine the dynamic process of the formation of common goals.

This research used data provided by a single informant from the marketing function in each firm. Past research has called for the perceptions of multiple functional areas on the grounds that perceptions differ among functions involved in NPD. For example, Song et al. [62] find that R\&D differs from marketing in the degree of importance it places on the determinants of performance, and Song et al. [69] show that marketing and R\&D managers differ in their preferences and criteria for evaluating cross-functional information.

The exploratory phase of the study excluded managers from mainland China. Thus, some of the constructs studied in this research may not apply to mainland China. In addition, our measures were all perceptual: Our data were subjective rather than objective. While this approach recognizes that variables such as goal incongruity (a perception) can be measured only by means of attitudinal scales, it also may have affected negatively the quality of the data. Moreover, some of our measurement scales, particularly those for joint rewards, exhibited low reliability. Since joint rewards proved to be significant in the regression equations, however, this lack of reliability does not appear to seriously have affected the results, except perhaps the within- and among-country comparisons.
This research was conducted at the program level rather than at the project level. While this allows the effects of firm-wide variables (such as top-management support for integration) to be identified, it does not address factors that contribute to the success of individual projects within a firm. Song and Xie [68] show that the characteristics of NPD projects, such as product innovativeness, can affect cross-functional integration patterns. Perhaps the importance of different antecedents of goal incongruity depends on the type of project.

\section{Suggestions for Future Research}

Future research might study the process of common goal formation and how it might be accommodated to increased time pressure in product development. It also might provide a more diverse view of the product development process by including the opinions of matched informants from multiple functions. Another promising study might investigate whether mainland Chinese managers share the same conceptual frameworks as their counterparts in China's special administrative region of Hong Kong. Future research at the project level might supplement the findings of the present program-level study by providing a more fine-grained view of the effect of goal incongruity on specific project types.

\section{References}

1. Allen, Thomas J. Managing the Flow of Technology. Boston, MA: MIT Press, 1977.

2. Ancona, Deborah G. "Outward Bound: Strategies for Team Survival in an Organization," Academy of Management Journal 33(2): 334-365 (1990).

3. Ayers, Doug, Dahlstrom, Robert and Skinner, Steven J. "An Exploratory Investigation of Organizational Antecedents to New Product Success," Journal of Marketing Research 34(1): 107-116 (1997).

4. Barclay, Donald W. "Interdepartmental Conflict in Organizational Buying: The Impact of the Organizational Context," Journal of Marketing Research 28(2): 145-159 (1991).

5. Baron, Reuben M. and Kenny, David A. "The ModeratorMediator Variable Distinction in Social-Psychological Research: Conceptual, Strategic, and Statistical Considerations," Journal of Personality and Social Psychology 51:1173-1182 (1986).

6. Bentler, Peter M. and Bonett, D.G. "Significance Tests and Goodness of Fit in the Analysis of Covariance Structures," Psychological Bulletin 88(6):588-606 (1980).

7. Berenson, Conrad. "The R\&D/Marketing Interface-A General Analogue Model for Technology Diffusion," Journal of Marketing 32(2): 8-15 (1968).

8. Bollen, Kenneth A. Structural Equations with Latent Variables. New York: Wiley, 1989. 
9. Boyacigiller, Nakiye Avdan and Adler, Nancy J. "The Parochial Dinosaur: Organizational Science in a Global Context," Academy of Management Review 16(2): 262-290 (1991).

10. Calantone, Roger J. and Di Benedetto, C. Anthony. Successful Industrial Product Innovation: An Integrative Literature Review. Westport, CT: Greenwood Press, 1990.

11. Calantone, Roger J. and Di Benedetto, C. Anthony. "Effective Management of the R\&D-Marketing Link for Improving New Product Success Rates," Journal of Managerial Issues 2(1): 75-90 (1990).

12. Daft, Richard L. and Lengel, Robert H. "Information Richness: A New Approach to Managerial Behavior and Organization Design," Research in Organizational Behavior 6:191-233 (1984).

13. Dillman, Don A. Mail and Telephone Surveys: The Total Design Method. New York: Wiley, 1978.

14. Douglas, S. and Craig, C.S. International Marketing Research. Englewood Cliffs, NJ: Prentice-Hall, 1983.

15. Erez, Miriam. "Toward a Model of Cross-Cultural Industrial and Organizational Psychology," In Handbook of Industrial and Organizational Psychology, ed. Harry C. Triandis, Marvin D. Dunnette and Leaetta M. Hough. Palo Alto, CA: Consulting Psychologist Press, 1994. pp. 559-607.

16. Feldman, L.P. "The Role of Salary and Incentives in the New Product Function," Journal of Product Innovation Management 13(3):216-228 (1996).

17. Garrott, June Rose. "Chinese Cultural Values: New Angles, Added Insights," International Journal of Intercultural Relations 19(2):211-225 (1995).

18. Gerbing, David W. and Anderson, James C. "An Updated Paradigm for Scale Development Incorporating Unidimensionality and Its Assessment," Journal of Marketing Research 25(2): 186-92 (1988).

19. Gerstenfeld, Arthur, Turk, Charles D., Farrow, Raymond L. and Spicer, Ronald F. "Marketing and R\&D," Research Management 12(6): 409-41 (1969).

20. Ginn, Martin E. and Rubenstein, Albert H. "The R\&D/Production Interface: A Case Study of New Product Commercialization," Journal of Product Innovation Management 3(3):158-170 (1986).

21. Gladstein, Deborah. "A Model of Task Group Effectiveness," Administrative Science Quarterly 29(4):499-517 (1984).

22. Gluckman, Ron. "The Americanization of China," Asiaweek 38: July 4 (1997).

23. Gomez-Mejia, Luis R. and Balkin, David B. "Effectiveness of Individual and Aggregate Compensation Strategies," Industrial Relations 28(3): 431-445 (1989).

24. Grant, Robert M. "Prospering in Dynamically Competitive Environments," Organizational Science 7(4): 375-387 (1996).

25. Griffin, Abbie and Hauser, John R. "Patterns of Communication among Marketing, Engineering, and Manufacturing-A Comparison between Two New Product Teams," Management Science 38(3): 360-373 (1992).

26. Griffin, Abbie and Hauser, John R. "Integrating R\&D and Marketing: A Review and Analysis of the Literature," Journal of Product Innovation Management 13(3):191-215 (1996).

27. Griffin, Abbie and Page, Albert L. "The PDMA Success Measurement Project: Recommended Measures for Product Development Success and Failure," 13(5): 478-96 (1996).

28. Gupta, Ashok K., Raj, S.P. and Wilemon, David. "A Model for Studying R\&D-Marketing Interface in the Product Innovation Process," Journal of Marketing 50(2): 7-17 (1986).

29. Gupta, Ashok K., Raj, S.P. and Wilemon, David. "R\&D and Marketing Managers in High-Tech Companies: Are They Different?," IEEE Transactions on Engineering Management 33(1): 25-32 (1986).
30. Hall, Edward T. Beyond Culture. New York: Anchor Press/ Doubleday, 1976.

31. Hofstede, Geert. Culture's Consequences. Beverly Hills, CA: Sage, 1980.

32. Hofstede, Geert. "Cultural Constraints in Management Theories," Academy of Management Executive 7(1): 81-94 (1993).

33. Hui, C. Harry and Tan, Chen K. "Employee Motivation and Attitudes in the Chinese Workforce," In The Handbook of Chinese Psychology, ed. Michael Harris Bond, Hong Kong: Oxford University Press, 1996. pp. 364-378.

34. Jaccard, James, Turrisi, Robert and Wan, Choi K. Interaction Effects in Multiple Regression. Newbury Park, CA: Sage, 1990.

35. Jiao, Shulan, Ji, Guipeng and Jing, Qicheng. "Comparative Study of Behavioral Qualities of Only Children and Sibling Children," Child Development 57(2):357-361 (1986).

36. Judd, Charles M. and Kenny, David A. "Process Analysis: Estimating Mediation in Treatment Evaluations," Evaluation Review 5(5):602-619 (1981).

37. Kahn, Kenneth B. and McDonough III, Edward F. "An Empirical Study of the Relationships among Colocation, Integration, Performance, and Satisfaction," Journal of Product Innovation Management 14(3):161-178 (1997).

38. Katzenbach, Jon R. and Smith, Douglas K. The Wisdom of Teams. Boston, MA: HBS Press, 1993.

39. Keller, Robert T. "Predictors of the Performance of Project Groups in R\&D Organizations," Academy of Management Journal 29(4): 715-726 (1986).

40. Kerr, Steven. "On the Folly of Rewarding A, while Hoping for B," Academy of Management Journal 18(4): 769-783 (1975).

41. Lange, Robert. "Participative Management as a Reflection of Cultural Contingencies: A Need to Reevaluate Our Ethic," In Japanese Management: Cultural and Environmental Considerations, ed. Sang M. Lee and Gary Schwendiman. New York: Praeger, 1982. pp. 117-134.

42. Latane, Bibb, Liu, James H., Nowak, Andrzej and Bonevento, Michael. "Distance Matters: Physical Space and Social Impact," Personality and Social Psychology Bulletin 21(8): 795-805 (1995).

43. Lawler, Edward A. Motivation in Work Organizations. Monterey, CA: Brooks/Cole Publishing, 1973.

44. Locke, E.A. and Latham, G.P. A Theory of Goal Setting and Task Performance. Englewood Cliffs, NJ: Prentice-Hall, 1990.

45. Maltz, E. and Kohli, A. "Market Intelligence Dissemination across Functional Boundaries," Journal of Marketing Research 33(1): 47-61 (1996).

46. Maidique, Modesto A. and Zirger, Billie Jo. "A Study of Success and Failure in Product Innovation: The Case of the U.S. Electronics Industry," IEEE Trans. Engineering Management 31(4): 192-203 (1984).

47. McCann, Joseph and Galbraith, Jay R. "Interdepartmental Relations." In Handbook of Organizational Design, ed. Paul C. Nystrom and William H. Starbuck. Oxford University Press, 1981. pp. 60-84.

48. Moenaert, Rudy K. and Souder, William E. "An Analysis of the Use of Extrafunctional Information by $R \& D$ and Marketing Personnel: A Review and Model," Journal of Product Innovation Management 7(3):213-229 (1990).

49. Nakata, Cheryl and Sivakumar, K. "National Culture and New Product Development: An Integrative Review," Journal of Marketing 60(1): 61-72 (1996).

50. O'Leary-Kelly, Anne M., Martocchio, Joseph J. and Frink, Dwight D. "A Review of the Influence of Group Goals on Group Performance," Academy of Management Journal 37(5): 1285-1301 (1994).

51. Olsen, Marvin E. The Process of Social Organization: Power in Social Systems. New York: Holt, Rinehart and Winston, 1978. 
52. Ouchi, William G. Theory Z. Reading, MA: Addison-Wesley, 1981.

53. Peter, J. Paul. "A Review of Psychometric Basics and Recent Marketing Practices," Journal of Marketing Research 16(1): 6-17 (1979).

54. Peter, J. Paul. "Construct Validity: A Review of Basic Issues and Marketing Practices," Journal of Marketing Research 18(2): 133145 (1981).

55. Pinto, Mary Beth, Pinto, Jeffrey K. and Prescott, John E. "Antecedents and Consequences of Project Team Cross-Functional Cooperation," Management Science 39(10): 1281-1297 (1993).

56. Porter, L.W. and Roberts, K.H. "Communication in Organizations," In Handbook of Industrial and Organizational Psychology, ed. Marvin D. Dunnette. New York: Wiley, 1983. pp. 1553-1589.

57. Putnam, Linda L. "Productive Conflict: Negotiation as Implicit Coordination," International Journal of Conflict Management 5(3): 284-298 (1994)

58. Rosenstein, Eliezer. "Cooperativeness and Advancement of Managers: An International Perspective," Human Relations 38(1): 1-21 (1985).

59. Ruekert, Robert W. and Walker Jr., Orville C. "Marketing's Interaction with Other Functional Units: A Conceptual Framework and Empirical Evidence," Journal of Marketing 51(1):1-19 (1987).

60. Sekaran, Uma. "Methodological and Theoretical Issues and Advancements in Cross-Cultural Research," Journal of International Business Studies 14(2):61-73 (1983).

61. Shapiro, Benson P. "Can Marketing and Manufacturing Coexist?," Harvard Business Review 55(5): 101-114 (1977).

62. Song, X. Michael, Montoya-Weiss, Mitzi M. and Schmidt, Jeffrey B. "Antecedents and Consequences of Cross-Functional Cooperation: A Comparison of R\&D, Manufacturing, and Marketing Perspectives," Journal of Product Innovation Management 14(1): 35-47 (1997).

63. Song, X. Michael and Parry, Mark E. "R\&D-Marketing Integration in Japanese High-Technology Firms: Hypotheses and Empirical Evidence," Journal of Academy of Marketing Science 21(2): 125-133 (1993).

64. Song, X. Michael and Parry, Mark E. "The Determinants of Japanese New Product Success," Journal of Marketing Research 34(1): 64-76 (1997).
65. Song, X. Michael and Parry, Mark E. "What Separates Japanese New Product Winners from Losers," Journal of Product Innovation Management 13(5): 422-39 (1996).

66. Song, X. Michael, Thieme, Jeffrey R. and Xie, Jinhong "The Impact of Cross-Functional Joint Involvement across Product Development Stages: An Exploratory Study," Journal of Product Innovation Management 15(4): 289-304 (1998).

67. Song, X. Michael, Xie, Jinhong and Dyer, Barbara. "Antecedents and Consequences of Marketing Managers' Conflict Handling Behaviors," Journal of Marketing 64(1): 50-66 (2000).

68. Song, X. Michael and Xie, Jinhong "Does Product Innovativeness Moderate the Relationship between Cross-Functional Integration and New Product Performance in Japanese and U.S. Firms?" Journal of International Marketing 8(4): 61-89 (2000).

69. Song, X. Michael, Xie, Jinhong and Di Benedetto, Anthony C. "Information Attributes, Market Uncertainty, and Cross-Functional Information Processing: Hypotheses and Empirical Evidence from the U.S. and Japan," IEEE Transactions on Engineering Management 48(2): 223-238 (2001).

70. Souder, William E. Managing New Product Innovations. Lexington, MA: Lexington Books, 1987.

71. Tjosvold, Dean. "Effects of Shared Responsibility and Goal Interdependence on Controversy and Decision-Making between Departments," Journal of Social Psychology 128(1): 7-18 (1987).

72. Triandis, Harry C., Bontempo, Robert and Villareal, Marcelo J. "Individualism and Collectivism: Cross-Cultural Perspectives on Self-Ingroup Relationships," Journal of Personality and Social Psychology 54(2): 323-338 (1988).

73. Van de Ven, Andrew H. "Central Problems in the Management of Innovation," Management Science 32(5): 590-607 (1986).

74. Wagner III, John A. "Studies of Individualism-Collectivism: Effects on Cooperation in Groups," Academy of Management Journal 38(1): 152-172 (1995).

75. Walton, Richard E. and Dutton, John M. "The Management of Interdepartmental Conflict: A Model and Review," Administrative Science Quarterly 14(1): 73-84 (1969).

76. Workman, John P. "Marketing's limited role in new product development in one computer systems firm," Journal of Marketing Research 30(4): 405-421 (1993).

77. Xie, Jinhong, Song, X. Michael and Stringfellow, Anne. "International Conflict, Conflict Resolution Styles, and New Product Success," Management Science 44(12): 192-S206 (1998).

\section{Appendix A. Measurement Scales}

All items were scored on seven-point scales. Except where otherwise stated, the scales were anchored by "Strongly Disagree" and "Strongly Agree."

Harmony of Cross-Functional Relationships (adopted from Song et al. [67])

1. Overall, we are satisfied with the relationship between our department and the other two departments.

2. All three departments try their best to carry out the responsibilities and commitments made to each other.

3. There is a give-and-take relationship among the three departments.

4. There is open communication among the three departments.

Quality of Cross-Functional Information (adopted from Song et al. [67])

1. The information presented by one department to the others is accurate.

2. In general, information from the other two departments lacks credibility with this department. (Reversescored)

3. Our cross-functional communications are often timely. 
Level of Cross-Functional Involvement (adopted from Song et al. [67])

The scales for this measure were anchored by "Never" and "Always."

In general, to what extent does each of the three departments currently get involved and/or share information in each of the following activities of the new product development process:

1. R\&D is involved in analyzing market opportunities?

2. R\&D is involved in visiting major customers?

3. Manufacturing is involved in visiting major customers?

4. Manufacturing is involved in test marketing/trial selling prior to launch?

5. Marketing is involved in determining desired product features?

6. Marketing is involved in working continuously for quality improvements?

Goal Incongruity (adopted from Song et al. [67])

1. The goals are different among marketing, $\mathrm{R} \& \mathrm{D}$, and manufacturing departments.

2. The criteria for making decisions are different among marketing, $\mathrm{R} \& \mathrm{D}$, and manufacturing.

3. Time orientations are different among marketing, R\&D, and manufacturing.

Joint Reward System (adapted from Song et al. [67])

1. Our senior management promotes team loyalty over functional loyalty.

2. Team members are evaluated based on the team performance instead of individual performance.

3. All three departments share equally in the rewards from a successfully commercialized new product.

Top-Management Support for Integration (adopted from Song and Parry [64])

1. Our management formally promotes cross-functional teamwork.

2. Our management sets clear objectives and high standards for teamwork.

3. Our management requires we get a consensus on all new product decisions.

Physical Proximity (adopted from Maltz and Kohli [45])

There are physical barriers (department location, geographic separation) that make it difficult for us to communicate. (Reverse-scored)

Job Rotation (adopted from Song et al. [67])

1. Planned job rotation of employees and managers is emphasized as a device for developing their capabilities.

2. We rotate employees across functional areas such as R\&D, manufacturing, and marketing.

Table A1. Demographic Data on the Respondents

\begin{tabular}{|c|c|c|c|c|c|}
\hline & $\begin{array}{l}\text { US } \\
(n=256)\end{array}$ & $\begin{array}{l}\text { GB } \\
(n=214)\end{array}$ & $\begin{array}{l}\text { Japan } \\
(\mathrm{n}=279)\end{array}$ & $\begin{array}{l}\mathrm{HK} \\
(\mathrm{n}=119)\end{array}$ & $\begin{array}{l}\text { China } \\
(n=215)\end{array}$ \\
\hline Age & $\begin{array}{c}49.60 \\
(10.91)\end{array}$ & $\begin{array}{l}47.70 \\
(11.22)\end{array}$ & $\begin{array}{c}49.32 \\
(10.44)\end{array}$ & $\begin{array}{l}50.60 \\
(9.83)\end{array}$ & $\begin{array}{c}46.47 \\
(11.40)\end{array}$ \\
\hline $\begin{array}{l}\text { Years of Working } \\
\text { Experience }\end{array}$ & $\begin{array}{l}29.98 \\
(5.57)\end{array}$ & $\begin{array}{l}27.36 \\
(5.95)\end{array}$ & $\begin{array}{l}27.81 \\
(5.82)\end{array}$ & $\begin{array}{l}28.29 \\
(5.34)\end{array}$ & $\begin{array}{l}26.57 \\
(5.92)\end{array}$ \\
\hline $\begin{array}{l}\text { Number of } \\
\text { People Reporting } \\
\text { to the Manager }\end{array}$ & (731) & 1,025 & (741) & (816) & (662) \\
\hline
\end{tabular}


Copyright $\odot 2003$ EBSCO Publishing 